DOI 10.5937/kultura1235320D

UDK 316.722

81'26/.'27:316.7

originalan naučni rad

\title{
PRIRODNOSTANJE
} MULTKULIURALLZMA

Sažetak: U radu se na skokovit način čitaocima predočava aktuelnost teme multikulturalizma danas. To polje, kao večito neiscrpno, postalo je aktuelno u drugačijim formama istraživanja. Tekst se ne bavi sistemom obrazovanja temeljno i direktno, ali ima za cilj da multikulturalizam predstavi u kontekstu teme obrazovanja i važnost poznavanja više kultura $i$ više jezika.

Ključne reči: multikulturalizam, jezik, ekolingvistika, separatizam

„,Na susretu predstavnika Samija i predstavnika norveške vlade, neko je upitao jednu Samijku da li joj treba prevodilac. Ne treba, odgovorila je ona, ali ja ću govoriti na samijskom, pa će možda trebati vama".

Dejvid Kristal prema Trond Trosterud

Iz našeg gore navedenog citata o Samijki koja potiče sa severa Norveške, hteli smo da ukažemo koliko pitanje kulture i upotrebe jezika može da ispolji stav kako lično, tako i mogućnost da se tim ličnim stavom pokrene lavina pitanja, nedoumica, sukoba i oprečnih stavova. Jezik pominjemo u različitim kontekstima, kako bismo na osnovu njegovo sudbine u društvu, kao jednom od elemenata koji se navodi kao obeležje etničke grupe, pokušali da pokažemo koliko mi danas, na primer, u sistemu obrazovanja pravimo propuste u mogućnostima da unapredimo multikulturalnost. Multikulturalizam se danas sve više i sa raznih strana dovodi u pitanje, što samo po sebi i ne bi moralo da bude loša stvar. Pravi problem je porast rasizma i etničkih tenzija, čemu je, između ostalog, multikulturalizam trebalo da bude brana. Svedoci smo i da oni koji zastupaju rasističke, nacionalističke i slične stavove žele da njihovi stavovi imaju jednako pravo gra- 


\section{IVANA ĐOKOVIĆ}

đanstva u javnoj debati. ${ }^{1}$ Sva kulturna obeležja bilo Mađara, Rusina, Slovaka ili bilo koje druge nacionalne manjine, svoju vrednost žele isključivo prvo da istaknu na osnovu zasebnog jezika, te se nekada sama umetnička vrednost potiskuje. Pitamo se da li pogrešnim postavljanjem određenih ,pravila“ funkcionisanja u državnom uređenju štetimo nepovratno i sebi i drugima, a ono gde se šteta najteže uklanja, čega se retko setimo, jeste u međukulturnim vezama. Jedna dobra ilustracija ove teme je život i njegov prestanak u državi Jugoslaviji, i ponovna, kao da je reprizirana, epizoda o ozvaničenju crnogorskog jezika u novije vreme. Do zvaničnog današnjeg naziva se dolazilo, naoko postepeno, kao što je Crna Gora postepeno izlazila iz zajedničke države sa Srbijom. Činjenica je da su previranja išla preko jezika i kulture da bi se konačno znalo ko pripada kojoj etničkoj grupi. Nove a opet stare političke platforme su izrodile takođe nove (a stare) nacionalne manjine u pojedinim delovima druge države, i polje multikulturalizma postaje sve kompleksnije i bogatije za razmatranje. Ukoliko želimo da se utešimo da nemamo samo mi pune ruke posla možemo pogledati stanje u kojem je velški jezik, te ćemo uvideti posebne složenosti. S jedne strane sudbina velškog je zapečaćena u skladu sa starosnom granicom, i to je činjenica koja je stvarala sukobe u samoj zajednici po pitanju očuvanja identiteta putem života jezika, s druge strane ekstremni stavovi podgrevali su loše okolnosti. Postoji anegdota koja govori da je jednom prilikom Velšanin, obavljajući svoju odborničku dužnost, pošao u Gvinedu (sever Velsa) kako bi podneo izveštaj. Službenik mu je zamerio, naime, ne zato što ima bilingvalan izveštaj, što je u tim prilikama bilo pohvalno, već što je u toj jezičkoj ekvivalenciji izveštaj prvo bio napisan na engleskom, a zatim na velškom. ${ }^{2}$ Ovakvu zamerku onaj ko nema ličnu potrebu da forsira svoj jezik na ekstreman način doživljava možda kao uvredu ili opet kao stvaranje otpora borbi za očuvanje te iste ideje, koju država pokušava da sprovede. Ovakva situacija podseća na položaj današnjih Ukrajinaca (i donekle Rusina) u Vojvodini koji, s jedne strane, imaju zavidan odnos prema očuvanju i negovanju svoje kulture, takav da može poslužiti kao primer drugima, ali i određenu dozu otpora novih generacija kroz školski sistem, koji im to očuvanje, priznajemo, nameće na jedan veštački način. Može se navesti još niz situacija u našem životu, ne uzimajući u obzir samo primer nekadašnjih rivaliteta na relaciji srpsko-hrvatski, već i primere iz heterogenih sredina kao što je Vojvodina. Koliko izazova nosi multikulturalizam npr. i ruskom jeziku vidi se iz primera ukra-

1 Upor. Prnjat A., Antisemitski diskurs kao jezičko - ekspresivni paternalizam, Kultura broj 134, 2012, str. 395.

2 Kristal D., Smrt jezika, Beograd 2003. 


\section{IVANA ĐOKOVIĆ}

jinskog Zakona o jezicima. Interesantno je da ukrajinski zakon dozvoljava korišćenje bilo kog drugog jezika na regionalnom nivou, a da se pritom ne imenuje na koji se jezik ova napomena odnosi, doduše uz ogradu da je uslov prihvatljivost datog jezika u populaciji tog kraja. Naravno, u ovakvim situacijama često biva da nijedna strana ne bude u potpunosti zadovoljna. Ovde je zanimljivo da se posle potpune pobede ukrajinskog jezika, ruski jezik izjednačava sa drugim jezicima nacionalnih manjina na jedan čudan način. Naime Ustav u članu 10 kaže „U Ukrajini se garantuje slobodan razvoj, upotreba i zaštita ruskog i ostalih jezika nacionalnih manjina Ukrajine“"3. Da li je ovakvo rešenje zadovoljavajuće ili, preciznije rečeno, da li se ovakvim gestom smatra da je nađena srednje rešenje povoljno za sve? Možemo se pitati da li je ispravno iz statusa onih jezika koji su proglašeni jezicima nacionalnih manjina, postaviti jedan od njih u privilegovan položaj? Jasno je da je ukrajinsko rešenje doneto na osnovu činjenične rasprostranjenosti ruskog jezika i broja njenih govornika. Zapravo, iza ovog rešenja se kriju stavovi onih koji ne žele ravnopravnost ukrajinskog jezika sa ruskim iz razloga koji opet dokazuju pozadinu. Razlozi koji su korišćeni kao argumenti su: zaobići iz istorijskih razloga uticaj ruske kulture, te da se pod okriljem bilingvizma prikrije jak uticaj ruskog, zatim, ukoliko ukrajinski dozvoli rivalitet, odmoći će se u cilju građenja ukrajinske nacije, i konačno, ruski jezik bi doprineo tehnološkoj i kulturnoj zavisnosti od Rusije čime bi se pospešio ruski imperijalizam. Ovde ne smemo ispustiti iz vida koliko se pod uticajem povlačenja političkih poteza dolazi do surove realnosti da je bilingvizam, kulturno dragoceno bogatstvo, shvaćeno kao potpuna pretnja za ljude i društvo uopšte. Da li tinejdžeri koji pohađaju svoje škole, ili studenti, imaju prilike da postavljaju konkretna pitanja i gde mogu da nađu odgovore, jer se odluke tiču direktno kvaliteta njihovog obrazovanja? Kako oni nezadovoljni (uključujući i roditelje) mogu da utiču? Stvar biva još komplikovanija za analizu ukoliko se ima u vidu da Ukrajina, ali ne samo Ukrajina, ima izuzetno složenu realnost po pitanju religijskih razlika. Poznato je da su ukrajinski pravoslavci podeljeni u tri crkve koje su jedna drugoj suprotstavljene, i takođe da ukrajinska grko-katolička crkva ima znatnu ulogu.

Naime, navodeći u ovom tekstu primere iz iskustava različitih država, mi ne želimo da stanemo u odbranu nekih jezika i kultura jer ih smatramo većim ili bitnijim od drugih (iako se baš ruski jezik oštro bori na sceni svetskih jezika). Ne postoje mali ili veliki

3 Fesenko V., Perspektive liberalno-pluralističkog pristupa etničkim manjinama u Ukrajini, u: Može li se izvoziti liberalni pluralizam, priredili Kimlika V. i Opalski M., Beogradski centar za ljudska prava, Beograd 2002, str. 247259. 


\section{IVANA ĐOKOVIĆ}

jezici, i obrazovanje mora da se orijentiše na ovu naučnu istinu. Ima mišljenja da u obrazovnoj politici ne bi trebalo da odlučuje monolingvalna osoba, koja možda ne bi shvatila ovakve stavove. S druge strane, ima nekih naznaka da bi bilingvalna osoba mogla da predloži dobre odgovore ili, još bolje, osoba koja potiče iz mešovitog braka. Ovakvi stavovi izvučeni su pre svega na osnovu suživota u Vojvodini i ne bi ih trebalo uzimati kao konačne, naravno. Ali podsetimo se da je lingvista svetskog glasa Dejvid Kristal, istakao da je čovekovo prirodno stanje multilingvalnost (nas ovde ovakva misao navodi da je i prirodno stanje multikulturalnost). On tvrdi da je čovekov mozak predodređen za više jezika i očigledno je da većina ljudi uspešno ovaj dar koristi. Oni koji su navikli na prevagu isključivo monolingvalnosti u njihovoj sredini teško pristaju da se situacija menja, jer promenu na psihološkom planu doživljavaju kao atak. Ovaj atak se često može objasniti (ali da li i opravdati?) lošim društvenopolitičkim prilikama koje su zadesile pojedine narode. U ovakvim nezrelim okolnostima primećujemo da su razmere društvene, kulturne, religijske, obrazovne i mnoge druge štete neprocenjive.

Branimir Stojković, pozivajući se i na druge teoretičare, podseća da se diskurs multikulturalizma podudara sa pristalicama ekopokreta. ${ }^{4} \mathrm{U}$ ovakvom pronicljivom uspostavljanju veze, pa i dovođenjem te veze u sklad sa relacijom ka biološkoj raznovrsnosti, moramo da se nadovežemo sa još jednom vrstom ekologije. Naime, ovakva postavka neodoljivo podseća na ekolingvistiku, koja na najpotresniji način sagledava smrt jezika (pritom se misli na bilo koji jezik pa makar i sa jednim živim govornikom). Ekolingvistika bi mogla danas da da mnoge odgovore na dileme u obrazovanju, ali bi njenu definiciju trebalo podrobnije približiti, odnosno razgovarati o tome šta bi ekolingvistika mogla da pruži obrazovanju, ili na koje se sve načine doživljava svet koji nas okružuje, kako mu se prilagođavamo i šta u sebi nosi svaki preživeli običaj, ili bolje rečeno, šta je u nepovrat odneo onaj koji je izumro. ${ }^{5}$ Gramatička struktura i neprocenjivosti njene dubine poznati su lingvistima, ali smatramo da se široj javnosti moraju predočiti ove prednosti, ne bi li imali relevantniji put ka prihvatanju i uočavanju pogrešno postavljenih teza današnjeg života u multinacionalnim sredinama. Istina, bez podrške medija, što nosi izvestan deo atraktivnosti, teško da bismo postigli rezultate. S ovim se i otvara nova tema medija danas, kada, kao što je poznato, nismo samo u dobu mnoštva televizijskih, radio-stanica

4 Stojković B., Kulturni kanon i multikulturalna društva, u: Savremena drža$v a$, Konrad Adenauer Stiftung i Fakultet političkih nauka, Beograd 2008, str. 212.

5 Više o ovome: Kristal D., Smrt jezika, Biblioteka 20. vek, Beograd 2003. 


\section{IVANA ĐOKOVIĆ}

ili mobilnih telefonija već, kako to primećuje Divna Vuksanović, u sferi Metaverzuma. Mediji su danas u službi, direktno ili indirektno, spektakularnosti, te ukoliko tema nije medijski interesantna - ostaje po strani. Kroz novi pristup obrazovanju, još od nižih dečijih uzrasta, svakako smo mogli da naučimo u samim tim medijima da razlikujemo i primetimo ,jedan obrt u vezi sa pojmom istine, koji se svakako ne bi dogodio bez upliva medija u domen njegovog istraživanja“, napominje Divna Vuksanović u tekstu Savremeni mediji i društvena istina. ${ }^{6}$

Kimlika smatra da će „većine u demokratskoj političkoj zajednici, na bilo kojem nivou, koristiti svoju moć da privileguju svoj jezik, kulturu i identitet, i pokušavaće da odrede političku zajednicu preko karakteristika većine. Manjine će odgovarati zahtevajući određene oblike prava i moći koje će ih zaštiti od potencijalnih nepravdi, koje su implicitne ovakvoj politici građenja nacije zasnovanoj na većinskom principu. Možda će se mesto na kojem se odigrava proces donošenja odluka promeniti, ali dijalektika građenja nacije i manjinskih prava neće nestati“"7. Primećujemo da koliko god je nauka davala odgovore često je uzmicala pred velikim eksponiranjem kada je u pitanju relacija jezika i nacije, jer je svesna da je ovaj odnos najosetljiviji za empirijsku analizu i interdisciplinarna razgraničavanja, tim pre što se u društveno-političkim momentima više unosilo emotivnog žara, nego što se pribegavalo objektivnosti. Činjenica jeste da definicije nisu potpuno razgraničene, $t j$. da postoje više sličnih po pitanju pojmova etnička grupa, narod i nacija. Ranko Bugarski u knjizi Jezik u društvu piše da je etnička grupa ostavljena za manje formacije, dok se narod može etnički mešati. Ističe da su nacije pogotovo predodređene za velika mešanja koja su u praksi zapravo retko etnički jedinstvene, pa samim tim su i meta za političke i druge društvene uloge. Tradicionalno shvatanje je vezano za pojam naroda dok se za naciju vezujemo svojim stečenim odabirom i slobodnom voljom. Kada se na naciju pristaje opredeljenjem, etnički momenat odlazi u drugi plan, mada smo svedoci koliko pod određenim okolnostima prihvaćene obaveze mogu da budu drastične, kada u društvu okolnosti krenu po zlu. Jedan narod može sam da obrazuje naciju, ili da se udruži sa drugim narodima u jednu naciju. Ovakve primere smo videli kod slovenskih naroda ili na primeru kanadskog. Obrnut proces od ovih je pak težnja da se raznorodni ,etnički sastojci“ homogenizuju. Ovakvu situaciju zatičemo u SAD prilikom njenog postupanja prema imigrantskoj populaciji. Melting pot je očigledan

6 Pogledati tekst Vuksanović D., Savremeni mediji i društvena istina, Kultura polisa.

7 Kimlika V., Može li se izvoziti liberalni pluralizam?, Beogradski centar za ljudska prava, Beograd 2002, str. 353. 
proces hitne amerikanizacije i predstavlja dugogodišnju politiku Amerike. Ipak, kako je država jačala, postalo je jasno da je strah od uvođenja još jednog jezika, pored engleskog, bespredmetan. Ovakvi potezi potvrđeni su u zajedničkom jeziku sa Kanadom, Australijom, Velikom Britanijom, ali i drugim zemljama u kojima se koristi engleski, te je shvaćeno kolika prednost je nastala u pospešivanju komunikacije ili izgradnji tzv. kulturnog mosta među narodima iz različitih delova sveta i različitog porekla. Kada je, kako kaže Ranko Bugarski, voda ispod „lonca za pretapanje“" počela da nestaje, moglo se uvideti da taj isti lonac nije pretopio etničke posebnosti koje su se održale na osnovama religije ili običaja. I danas je ukorenjeno shvatanje na relaciji jezik - nacija - država, da je prirodno da svaka ljudska zajednica koja je došla do stepena nacije, ima svoj jezik, što po tom shvatanju podrazumeva i posebnu državu. Upravo ovo i jeste jedan argument koji je koristila Ukrajina, pozivajući se na to da je ponovno rođenje nacije nemoguće bez njenog jezika. (Ovakvim stavovima može da se predstavi primer etničke svesti Roma, Jevreja ili Kurda). Kroz određenu dozu mistifikacije i ukorenjene mitologije možemo se složiti sa stavovima da se pripadnost grupi konstituiše ne samo na sociopolitičkim relevantnim činjenicama ili istorijskim osnovama, već i na subjektivnim osećanjima.

Dakako i naši autori i eksperti iz ovih oblasti imaju pune ruke posla kako rešiti miltikulturalnu enigmu koja potresa sve stanovnike naše države i regiona. Zato kada govorimo o teorijama koji prezentuju autori iz Zapadne Evrope ili bilo kojeg kraja sveta, moramo biti zainteresovani i pokušati da određene modele uzmemo u obzir kao i dobronamerne savete. Tibor Varadi je primetio da stavovi Vila Kimlike, koji sa jedne strane zagovaraju prestanak podela ljudi prema ,etnokulturalnoj afilaciji“ (kada se dostigne zavidan stepen dostupnosti institucija svim građanima), ali sa druge strane tvrde da će ekonomski razvoj doprineti stabilizaciji podela na osnovu etnoklulturalne pripadnosti, nisu naročito uverljivi ako se poznaju prilike u bivšoj Jugoslaviji.

No, znajući da se zavidan nivo modernizacije nije dosegao, ovakvi stavovi se doduše nisu mogli ni sasvim realno proveriti. Ukoliko bismo mogli, što i sam Tibor Varadi kaže, potvrditi da je ovakva mogućnost realna (jer ljudima jeste prioritet ekonomsko blagostanje, što bi dovelo do smanjenja tenzija), ne smemo izostaviti važnost etnokulturne pravde koja se mora uzeti u obzir kako god se proces odvijao. Ukoliko bi se isključio identitet nekoj zajednici, teško da bi se mogla očekivati lojalnost državi, ali bi ona bila utoliko veća ukoliko bi se nacionalnim manjinama obezbedilo pravo na upotrebu jezika, što bi odmah tu zajednicu ohrabrilo da se oseća kao deo države (što ona i jeste), a nikako otuđenu i sputanu od društva. Sa pravom Varadi govori da bi 


\title{
IVANA ĐOKOVIĆ
}

se zapadni modeli mogli uzeti kao relevantni u momentu kada većina zemalja teži NATO-u kako bi se približili standardima Evropske unije. Ukoliko se povinujemo osećanju stalne sumnje u lojalnost nacionalnih manjina državi i predrasudama o vrsti posla koju bi trebalo da obavljaju (kako bi bili distancirani od štete koje bi nam navodno mogli naneti), imaćemo večitu nazadnu sliku i u obrazovanju, a samim tim i šire na društvenom planu. Ukoliko bismo na ovim pitanjima aktivno radili od samog predškolskog koncepta, smatramo da bismo imali delotvornije rezultate uz mogući rizik da se naiđe na negodovanje većine koja nije sklona poverenju u promene. Samim tim prevaziđeni pristupi traže nove. Pristupi obojeni i podržani novim idejama postoje, samo bi ih trebalo dosledno primeniti i očekivati da se određena doza atraktivnosti pokaže što pre.

\section{LITERATURA:}

Bugarski R., Jezik u društvu, Čigoja, Beograd 2007.

Kimlika V. i Opalski, M., Može li se izvoziti liberalni pluralizam?, Beogradski centar za ljudska prava, Beograd 2002.

Kristal Dejvid., Smrt jezika, Biblioteka XX vek, Beograd 2003.

Petrović D., Geopolitički aspekti savremene Ukrajine.

Prnjat A., Antisemitski diskurs kao jezičko-ekspresivni paternalizam, Kultura br. 134, 2012.

Stojković B., Savremena država, Konrad Adenauer Stiftung i Fakultet političkih nauka, Beograd 2008.

Stojković B., Evropski kulturni identitet, Službeni glasnik, Beograd 2003.

Vuksanović D., Savremeni mediji i društvena istina, Kultura polisa, god. VIII, br. 16.

\author{
Ivana Đoković \\ University of Belgrade, Faculty of Political Sciences, Belgrade
}

\section{NATURAL STATE OF MULTICULTURALISM}

\begin{abstract}
The paper leaps through the very actual topic of multiculturalism today. This ever inexhaustible field has become very interesting in other forms of research too. The text does not deal with the educational system directly or in great detail but it does aim at reviewing multiculturalism in the context of education and the significance of knowing more cultures and speaking more languages.
\end{abstract}

Key words: multiculturalism, language, eco-linguistics, separatism 